\title{
Increased reproductive output in stereotypic captive Rhabdomys females: Potential implications for captive breeding
}

\author{
Megan Anne Jones ${ }^{\mathrm{a}, *}$, Mathew van Lierop ${ }^{\mathrm{a}}$, Georgia Mason ${ }^{\mathrm{b}}$, Neville Pillay ${ }^{\mathrm{a}}$ \\ ${ }^{a}$ School of Animal, Plant, and Environmental Sciences, University of the Witwatersrand, Private Bag 3, Jan Smuts Avenue, Braamfontein, Johannesburg, WITS 2050 , \\ South Africa \\ ${ }^{\mathrm{b}}$ Department of Animal and Poultry Sciences, University of Guelph, 50 Stone Road East, Guelph, Ontario, Canada N1G 2W1
}

\section{A R T I C L E I N F O}

\section{Article history:}

Accepted 22 December 2009

Available online 22 January 2010

\section{Keywords:}

Conservation

External validity

Fitness

Reproduction

Stereotypic behaviour

Striped mice

\begin{abstract}
A B S T R A C T
Captive animal populations can diverge considerably from populations in the wild, despite the animals not being deliberately domesticated. If the phenotypes which are of benefit in captivity are heritable, the genotypes of captive-stock can diverge swiftly and substantially from wild-stock. Using striped mice, Rhabdomys, we tested the relationship between reproductive output and stereotypic behaviour, a heritable repetitive abnormal behaviour common in captive wild animals. Individuals $(n=120 ; 60 \hat{\text { s }}, 60$ \%) were assigned to pairs in one of four treatment groups formed from combinations of non-stereotypic and stereotypic mothers and fathers, and various measures of reproductive output were recorded. Reproductive output (e.g. total number of offspring) for stereotypic females (but not stereotypic males) was significantly greater than for non-stereotypic striped mice. We suggest that, overall, unintended selection is likely to increase the incidence of stereotypic behaviour in a captive striped mouse population because (1) stereotypic females breed more successfully than non-stereotypic striped mice, and (2) genetic variance underlies the trait. The potential implications of these findings for the validity of behavioural studies using captive-bred wild animals and for conservation breeding programmes are discussed. (c) 2010 Elsevier B.V. All rights reserved.
\end{abstract}

\section{Introduction}

Stereotypic behaviour in captive animals is caused by frustration and/or brain dysfunction (Mason, 2006a). Manifesting only in captivity, it affects at least 85 million domestic animals (Mason and Latham, 2004), as well as a significant proportion of captive wild animals housed in zoos (at least 10,000; reviewed in Mason et al., 2007) and laboratories (e.g. primates, Novak et al., 2006; roof rats, Rattus rattus, 100\%, Callard et al., 2000; bank voles, Clethrionomys glareolus, 30-50\%, Cooper et al., 1996; Ödberg, 1987; Schoenecker and Heller, 2000; striped mice, Rhabdomys, 57\%, Jones et al., in preparation). Whilst

\footnotetext{
* Corresponding author. Tel.: +27 11717 6400; fax: +27 114031429.

E-mail address: megan.jones@icon.co.za (M.A. Jones).
}

stereotypies typify sub-optimal environments (Mason, 1991; Mason and Latham, 2004), highly stereotypic individuals often show better welfare than less stereotypic conspecifics housed in similar sub-optimal conditions (Mason and Latham, 2004). Apparent benefits linked with stereotypic behaviour including reductions in heart rate (e.g. calves; Seo et al., 1998), and elevated reproductive success. In farmed mink (Mustela vison), for example, stereotypic females are sometimes more fertile and experience lower pup mortality than non-stereotypic females (Jeppesen et al., 2004; cf. Svendsen et al., 2007) and, in caged bank voles, stereotypic behaviour has recently been shown to be associated with better survival, fecundity, and therefore increased lifetime reproductive success (Schønecker, 2009). The mechanisms for such beneficial effects of stereotypic behaviour are unclear. It could be (1) that both stereotypy (Mason and Latham, 
2004) and increased reproductive success (Broom and Johnson, 1993; Wingfield and Sapolsky, 2003) reflect relatively low stress in sub-optimal cages; (2) that stereotypic behaviour has an indirect pleiotropic effect on reproductive success through its association with the directly selected trait of activity level or body condition, as is sometimes the case in mink (Jeppesen et al., 2004); or (3) that being of a fecund genotype predisposes animals to stereotypic behaviour, through genetic or epigenetic means, the latter perhaps influenced by litter-size mediated variations in the maternal care received in infancy (Priestnall, 1972).

Whatever the mechanisms behind this relationship, because stereotypic behaviour typically has a genetic component (bank voles, Ödberg, 1986; Schoenecker and Heller, 2000; mink, Jeppesen et al., 2004; Svendsen et al., 2007; domestic horses, Equus caballus, Kiley, 1977; Smith, 1984; striped mice, Jones et al., 2008; Schwaibold and Pillay, 2001), such findings strongly suggest that stereotypic genotypes may be selected for in captive conditions. Circumstantial evidence for this is that across a host of species, the F1 captive generation is more stereotypic than the wild-caught generation, although it is currently unknown whether this difference has a genetic, developmental, or environmental basis (Mason, 2006b); and that, in our randomly bred captive colony of Rhabdomys a greater proportion of F2 mice (56\%) than F1 mice (41\%) showed this behaviour (Fisher's Exact Test, $p=0.0011$; unpublished results).

Such effects are potentially important because when phenotypes which are favoured (selected for) in captivity are heritable, the genetic characteristics of captive animals can diverge swiftly and substantially from wild-stock (Lynch and Walsh, 1998; McDougall et al., 2006; McPhee, 2003). For example, in coonstripe shrimp, Pandalus danae (Marliave et al., 1993), just 10 generations of captive breeding caused changes in morphology, physiology, genotype, and ease with which they could be caught, despite there being no deliberate domestication; whilst in oldfield mice, Peromyscus polionotus subgriseus, generations of captive breeding resulted in diminished predator response behaviours, most likely because of relaxed natural selection pressures (McPhee, 2003). Such changes are undesirable if animals are part of conservation breeding programmes of which the central aim is to preserve the wild-type genetic and phenotypic characteristics of the species (Kleiman, 1996; McDougall et al., 2006; Snyder et al., 1996). For instance, it is suspected that bolder swift foxes, Vulpes velox, breed better than more fearful individuals in captivity but, upon reintroduction to their natural habitat, boldness predicts higher mortality (Bremner-Harrison et al., 2004). Such changes are also undesirable if captive-bred animals are being used to investigate phenomena occurring in wild individuals since these changes compromise the external validity of research findings.

Using Rhabdomys as a model, we assessed the relative reproductive success of stereotypic and non-stereotypic individuals. We set up four treatment groups, formed from combinations of non-stereotypic and stereotypic mothers and fathers. This design makes our study unique since we could assess the relative contribution of maternal and paternal stereotypic behaviours to reproductive output (cf. the recent work in bank voles examining only the maternal contribution; Schønecker, 2009), and thus test the prediction that both male and female stereotypic striped mice would reproduce more successfully than non-stereotypic mice.

\section{Methods}

\subsection{Model species}

Rhabdomys, the African striped mouse, is a small (40$70 \mathrm{~g}$ ), diurnal, muroid rodent that is widespread and abundant in southern African (Skinner and Chimimba, 2005). When captive-bred individuals are housed in standard laboratory cages, approximately half F1 mice develop locomotor stereotypic behaviour (e.g. circuit running; somersaulting; jack-hammering; and cageclimbing; see Jones et al. (2008) for detailed definitions of these behaviours). Our previous work in Rhabdomys has shown that this behaviour is genetically rather than socially transmitted (Schwaibold and Pillay, 2001), but with a greater maternal than paternal contribution to stereotypy development suggesting that maternally mediated epigenetic factors also influence the expression of the behaviour (Jones et al., 2008).

\subsection{Housing and husbandry}

All mice used in this study were housed in the Milner Park Animal Unit at the University of the Witwatersrand, under partially controlled environmental conditions (light regime of $14 \mathrm{~L}: 10 \mathrm{D}$, lights on at $05: 00 \mathrm{~h} ; 20-24{ }^{\circ} \mathrm{C} ; 30-60 \%$ relative humidity). Striped mice were kept in standard Labotec cages $(300 \mathrm{~mm} \times 200 \mathrm{~mm} \times 150 \mathrm{~mm}$ ) containing $\sim 2 \mathrm{~cm}$ woodshavings as bedding and a handful of hay as nesting material. Epol ${ }^{\circledR}$ mouse cubes (Epol, Pretoria West, South Africa) and water were provided ad libitum. We supplemented the diet twice weekly with a small amount $( \pm 5 \mathrm{~g})$ of a parrot seed mix.

\subsection{Procedure}

To obtain an appropriate sample size, we bred 40 wildcaught striped mice from a South African Highveld grassland locality $\left(25^{\circ} 40^{\prime} \mathrm{S} ; 28^{\circ} 30^{\prime} \mathrm{E}\right)$. The resultant F1 juveniles were weaned at 20 days, housed in same-sex sibling groups, and marked with hair dye for individual identification (Schradin and Pillay, 2004). From 30 days of age, we video-recorded the behaviour of the striped mice for $15 \mathrm{~min}$ twice weekly, for 7 weeks, to identify stereotypic and non-stereotypic individuals. Recordings took place between 08:00 $\mathrm{h}$ and 12:00 h, during which time Rhabdomys is most active (Pillay, 2000). No human observers were present in the room during taping. Because of the bimodal distribution of stereotypic behaviour in captive Rhabdomys populations (Fig. 1), we regarded animals that were consistently stereotypic (i.e. performed at least one bout in more than $60 \%$ ( $\geq 9$ of 14 ) of the independent observation sessions) as stereotypic, whereas 


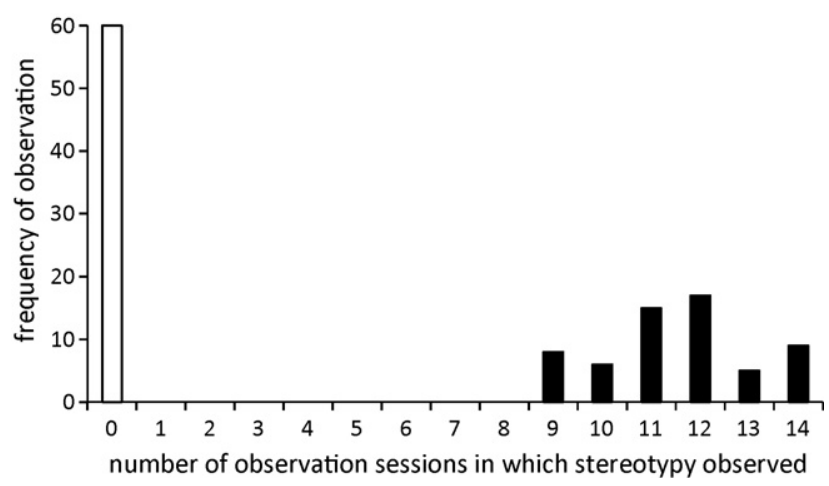

Fig. 1. Number of striped mice (total $n=120$ ) observed for stereotypic behaviour over a total of 14 independent observation sessions. We regarded animals that performed at least one bout of stereotypy in more than $60 \%$ ( $\geq 9$ of 14 ) of the observation sessions as stereotypic (black bars), whereas those that displayed none as non-stereotypic (white bar).

those that displayed none (during video recording, or in ad lib observations of the colony) were classed as nonstereotypic. We never recorded individuals with stereotypic behaviour in less than $60 \%$ of the observation sessions (see Jones et al. (2008) for the detailed scoring procedure and justification thereof).

When F1 mice were between 80 and 120 days old, we established 60 unrelated breeding pairs by assigning individuals to one of four treatments. Litters were equally represented in each of the four treatment groups. Treatment groups (15 pairs each), based on whether mice were stereotypic or non-stereotypic, were comprised as follows: (1) stereotypic female and stereotypic male ( $\mathrm{S}$ $\mathrm{S}$ ); (2) stereotypic female and non-stereotypic male (SoNS $)$ ); (3) non-stereotypic female and stereotypic male (NS $+\mathrm{S}^{\jmath}$ ) and (4) non-stereotypic female and non-stereotypic male (NS + -NS ${ }^{\wedge}$ ). Pairs were kept together for at least 100 days (in which time a maximum of three litters could be produced), and then separated only after the weaning of their final litter. Both the mother and the father were thus always present with the pups until weaning. Male striped mice, sometimes in the field and always in captivity, contribute equally to parental care and display similar behaviours to the mother, with the exception of suckling behaviour (Schradin and Pillay, 2004). Offspring were separated from their parents on day 20 (at least 3 days before another litter of pups would be born to the female), and then housed in same-sex sibling groups.

We recorded the number of successfully breeding pairs (pairs producing at least one litter) in each treatment and, for the successfully breeding pairs, the following measures: interval between pairing and birth of the first litter; inter-litter interval; number of litters; litter size at birth and at weaning; and the proportion of the litter surviving to weaning. We weighed the mothers and their litters on the day of birth (day 0) and again on day 20 (weaning), and calculated the pre-weaning average pup growth rates of litters using the formula [ $\ln ($ mass time 2$)-\ln ($ mass time 1)]/(time 2 - time 1$)]$.

\subsection{Ethical note}

Wild-caught mice were trapped using PVC live traps $(290 \mathrm{~mm} \times 60 \mathrm{~mm} \times 70 \mathrm{~mm})$. The traps were set for four nights, covered with grass to buffer temperature extremes, and baited with an excess (half a handful) mixture of rolled oats, raisins, salt, and sunflower oil. Moistened cotton wool was provided for water, and dry cotton wool as bedding. Traps were checked twice daily in the morning and late afternoon, immediately after activity peaks of Rhabdomys. This ensured that trapped individuals would be unlikely to spend more than $2 \mathrm{~h}$ in the traps. No trap deaths were recorded. Following capture, mice were transferred from traps into individual holding cages $(250 \mathrm{~mm} \times 250 \mathrm{~mm} \times$ $120 \mathrm{~mm}$, containing woodshavings for bedding and a handful of hay as nesting material, and provisioned with mouse cubes and a water bottle), and then transported to the University of the Witwatersrand-an approximately 60-min road trip.

After completion of this study, wild-caught mice were retained as breeding stock, whilst captive-born mice $(n=822)$ were used as subjects in other behavioural studies or euthanized $(n=257)$ using gradual-fill carbon dioxide euthanasia.

Approval for this study was granted by the Animal Ethics Screening Committee of the University of Witwatersrand (AESC: 2003/23/2A).

\subsection{Data analysis}

All analyses were performed using Statistica 7.1 (Statsoft Inc., Southern Africa). We compared the number of successfully breeding pairs in each treatment using logistic regression. General Linear Models (GLM), with maternal and paternal stereotypic status (and their interaction) as categorical predictors, were used to analyse the following variables: latency to produce a first litter, inter-litter interval, total number of litters produced, litter size at birth and at weaning (using a repeated measures design), total number of offspring born and total number of offspring surviving to weaning (using a repeated measures design), average pup growth rate (litter size was included as a continuous predictor to account for the effect of litter size on growth rate), and the proportion of offspring in each litter surviving to weaning (data were arcsine square root transformed; Zar, 1996). For pairs that produced more than one litter, we used average values for the litters produced per pair to avoid pseudoreplication. Tukey post 
hoc tests were used to identify specific differences when $\alpha \leq 0.05$.

\section{Results}

Table 1 provides the reproductive values measured in this study together with the statistical results. Significant findings are graphically represented in Fig. 2. The number of successfully reproducing pairs did not differ among the treatments. Maternal, but not paternal or maternal $\times$ paternal, stereotypic status was a significant predictor of the following variables: latency to first litter; litter size at birth and weaning; total offspring born and weaned; and percentage offspring survival to weaning. Post hoc tests revealed that stereotypic females had greater reproductive success (i.e. they produced more offspring, which grew faster and had better survival) than nonstereotypic females. The interaction between maternal and paternal stereotypies was a significant predictor of pup growth rate, with pups of stereotypic mothers (irrespective of paternal stereotypy) growing faster than pups in the

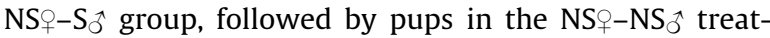
ment. Parental stereotypic status did not affect the total number of litters produced or inter-litter interval.

Since maternal mass is known to sometimes differ between stereotypic and non-stereotypic mink females, and to affect reproductive success (e.g. Jeppesen et al., 2004), we investigated this in these Rhabdomys. However, we found no mass difference between stereotypic and nonstereotypic mothers (Table 1) and controlling for dam mass in supplementary analyses did not change any of the results.

\section{Discussion}

Stereotypic behaviour in dams was associated with an increased reproductive output in striped mice. Compared to non-stereotypic individuals, stereotypic Rhabdomys mothers birthed (and weaned) nearly twice as many young within a 100-day period than did non-stereotypic females. Recording lifetime reproductive success could perhaps have yielded a more accurate estimate of the relative fitness of striped mice. However, such a protocol would have resulted in many surplus animals requiring euthanasia (see Section 4), and we suspect that our conclusions would not have changed since captive female striped mice show a sharp decline in reproduction after their third litter (Pillay, personal observation). In general, paternal phenotype did not affect reproductive success, with one exception: irrespective of paternal stereotypy, pups from stereotypic mothers grew faster than pups from non-stereotypic mothers but, in young from non-stereotypic dams, paternal stereotypy predicted a faster growth rate. These results therefore show, as predicted from other species, that stereotypic behaviour in Rhabdomys is associated with enhanced reproductive success.

The improved reproduction of stereotypic Rhabdomys shows both similarities to and differences from the similar findings reported for mink and bank voles (see Section 1) and is, to our knowledge, the first to measure the contribution of paternal stereotypy on reproductive

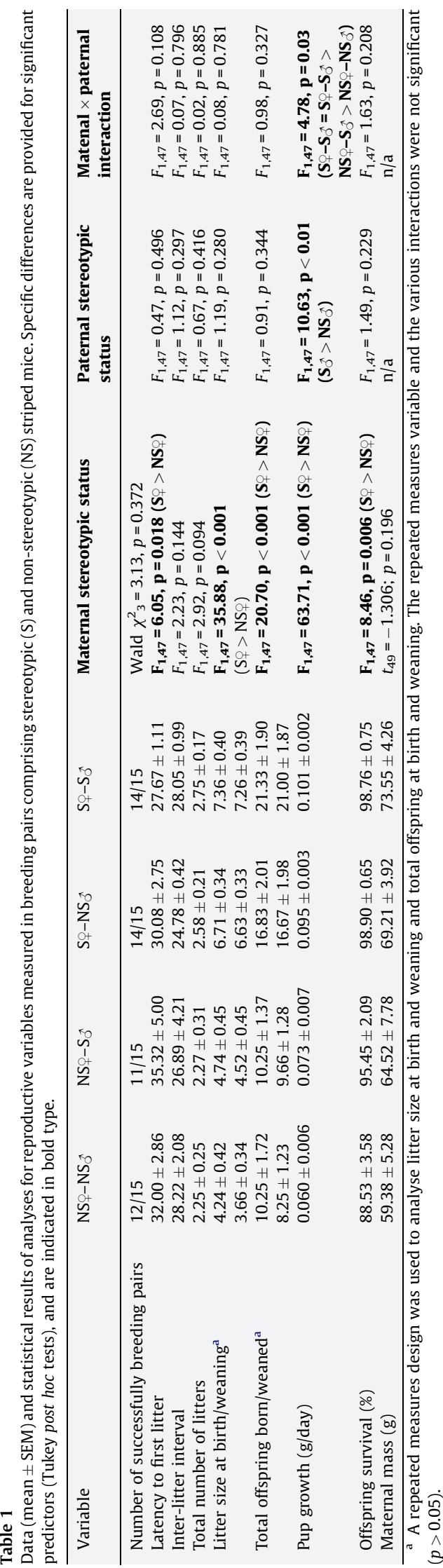



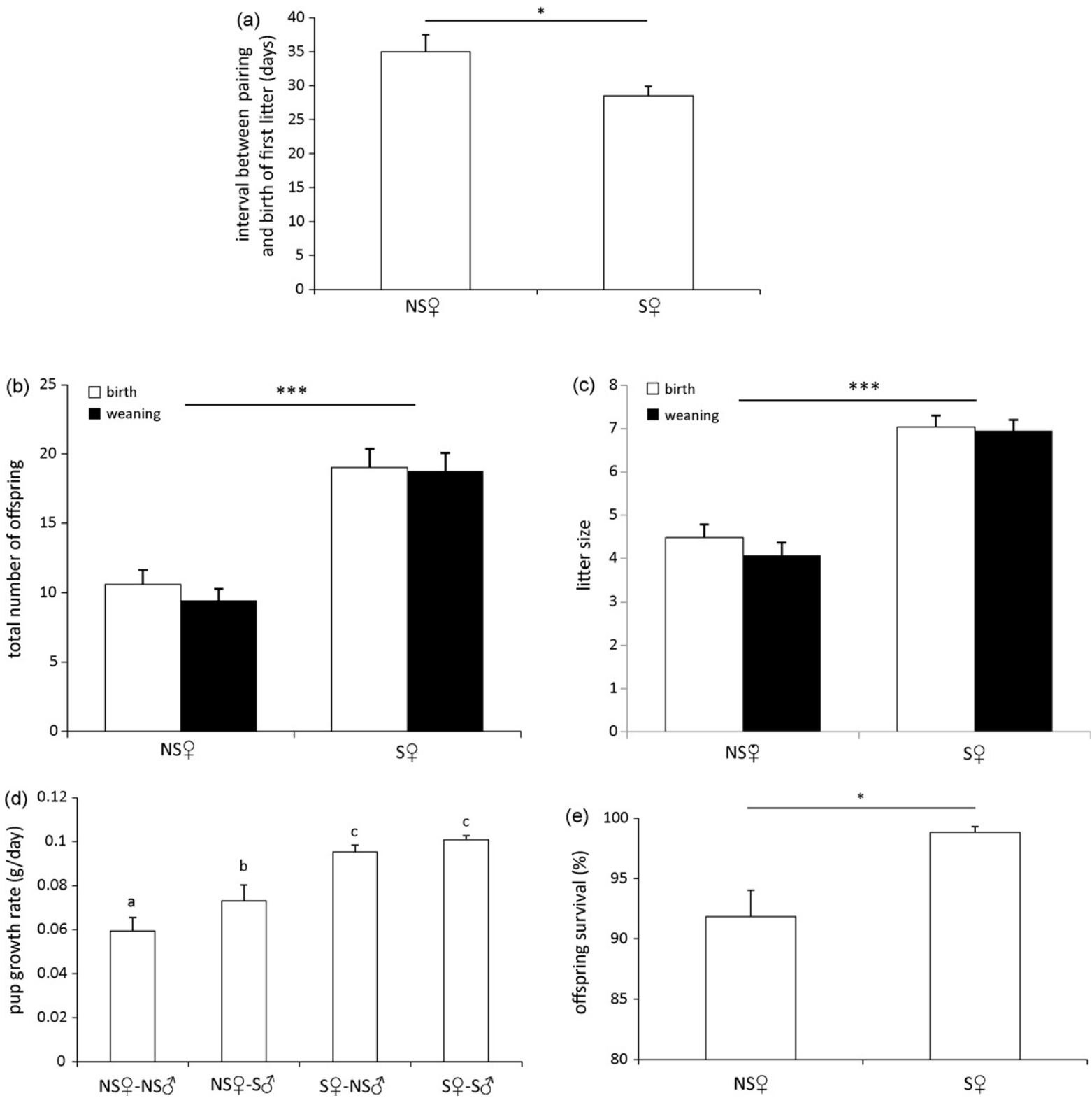

Fig. 2. (a-e) Five measurements (mean $+\mathrm{SE}$ ) of differential reproductive output in stereotypic (S) and non-stereotypic (NS) mice. If paternal or maternal $\times$ paternal stereotypic status did not predict the outcome, pooled mean + SE values are provided for the maternal effect only. Asterisks indicate significant differences between treatments $\left({ }^{*} p<0.05 ;{ }^{* * *} p<0.001\right)$. Alphabets show homogenous groups (from Tukey post hoc tests) when the maternal $\times$ paternal stereotypic status was a significant predictor of outcome.

parameters. In all three species, maternal stereotypic behaviour has been associated with improvement in at least some measures of fecundity. However, in mink, this relationship is not consistent across farms - Svendsen et al. (2007) found no differences in reproduction between high and low stereotyping lines of animals - and Jeppesen et al. (2004) study showed that the increased fertility and reduced pup mortality observed in stereotypic mothers could be better explained by the typically lower body weight of stereotypic dams, a mediating effect not observed in this study in Rhabdomys. Additionally, compared with Rhabdomys, the young of stereotypic mink females may grow more slowly in consequence of reduced levels of maternal care and the tendency of stereotypic dams to build less well insulated nests (Mason et al., 1995). The recent retrospective analysis of Schønecker (2009) showed that stereotypic bank vole mothers, similar to striped mice, have reduced latencies between pairing and the birth of their first litter but, in contrast to Rhabdomys, Schønecker (2009) found no difference in litter size or number of weanlings between stereotypic and nonstereotypic dams. Moreover, the study showed that the pups from stereotypic females sometimes experience higher pre-weaning pup mortality-replicating an effect observed in previous work on bank voles (Ödberg, 1987; Sørensen and Randrup, 1986). 
The consistent findings of increased fecundity across the three species discussed above suggest a widespread link between stereotypic behaviour and reproductive success. In Section 1 , we suggested three possible mechanisms through which this effect might occur. First, there might be a direct link between the variables if, for example, stereotypy and increased reproductive success both reflect better "coping" in sub-optimal caging. However, this seems unlikely in striped mice given that we have found no relationship between stereotypy and physiological (faecal corticosterone) or behavioural (e.g. behaviour in a light-dark box) measures of stress/anxiety (Jones et al., 2009). Second, the effect might be mediated via the pleiotropic promotion of stereotypic behaviour because it is indirectly related to a directly selected trait such as body condition (e.g. mink; Jeppesen et al., 2004), activity, or promiscuity. We have excluded the effect of body weight per se in Rhabdomys (although not of body composition), and our data argue against the pleiotropic selection for promiscuity because, whilst latency to first litter is shorter in stereotypic females, there is no difference in inter-litter interval, as would be expected if stereotypic striped mice were more likely to engage in impulsive sexual activity than non-stereotypic mice. Nevertheless, with our current data, we cannot examine whether body composition or activity (which is higher in stereotypic than non-stereotypic Rhabdomys; Jones et al., 2006) is a better predictor of reproductive success than the absence/presence of stereotypy. The third suggested mechanism was a potential direct link between a fecund and stereotypic genotype: again, we are unable to distinguish whether, for example, offspring born in larger litters are more prone to develop stereotypic behaviour (litter size also being a heritable trait/large litter size resulting in earlier weaning, which is known to predispose stereotypy in Rhabdomys as well as other species (Jones et al., in review), or whether the stereotypic phenotype directly/indirectly causes an increase in litter size.

A point of interest is why only female stereotypic Rhabdomys (and not males, with the exception of the effect of paternal stereotypic status on growth rate) showed higher reproductive output. This finding argues against a direct genetic link between fecundity and stereotypy being the sole mediator of the findings in this study, instead adding support to the second hypothesis that maternally mediated pleiotropic influences contribute to the observed differences in reproductive success. Future work should investigate whether differences between stereotypic and non-stereotypic dams in terms of activity level, body composition, and consequently hormonal profiles might have favoured reproduction in the stereotypic animals. Additionally/alternatively, the increased food consumption of stereotypic striped mouse females ( $\pm 3 \mathrm{~g}$ per day/41\% extra) suggests that the high activity levels of stereotypic Rhabdomys females confer the ability to maintain a reproductively favourable body weight and to concentrate dietary protein (Jones et al., 2006). As protein is critical for the initiation and success of reproduction in Rhabdomys (Nel, 2003; Perrin, 1980), differences in protein intake require direct testing in future studies.
Because stereotypic behaviour has a genetic basis in Rhabdomys, as in many other species (see Section 1), and since it is associated with increased reproductive success, stereotypy may thus increase in prevalence over successive generations of captive breeding-for which we already have preliminary evidence in striped mice (see Section 1). If confirmed, and found to be a widespread effect in captive wild animals, there could be considerable practical implications. First, genetic changes predisposing a high incidence of stereotypic behaviour could well be associated with selection for a correlated suite of behavioural traits which, whilst neutral or even adaptive in captivity, may be maladaptive in the wild. Whilst such variation in behaviour/temperament profiles is often maintained in populations in a frequency dependent manner (Gosling, 2001), shifts in the nature or strength of selection pressures, as will occur if stereotypic behaviour influences reproductive success, can move populations away from their adaptive optima and thus reduce the post-release survivorship of captive-bred individuals in conservation breeding programmes (e.g. Bremner-Harrison et al., 2004; Jule et al., 2008). A second potential problem is if stereotypic behaviour per se, and its underlying neurological causes (Garner and Mason, 2002; Lewis et al., 2006), compromises the abilities of released animals to behave appropriately (Vickery and Mason, 2003, 2004). Both this first and second problem will also raise doubt about the validity and replicability of laboratory based behavioural work in which the underlying assumption is that behavioural processes observed in the laboratory reflect those occurring in wild-type individuals in nature (Würbel and Garner, 2007). A third serious caveat is that if captive species are likely to become increasingly stereotypic, more ambitious attempts will be needed to enrich their environments to reduce this aesthetically undesirable behaviour (e.g. Swaisgood, 2007; Swaisgood and Shepherdson, 2005, 2006).

\section{Conclusion}

Overall, the consistently and dramatically improved reproductive output of stereotypic female Rhabdomys (and higher growth rates conferred by the genotypes of both parents) suggests that stereotypic behaviour, manifested only in captivity, has positive fitness correlates in captive conditions. It also suggests that stereotypic behaviour could possibly signal a captive environment that is placing animals under very different selection pressures from those occurring in the wild, with unintended selection likely to further increase the incidence of stereotypic behaviour in captive populations. This has potential implications for the validity of behavioural studies using captive-bred wild animals and for conservation breeding programmes.

\section{Acknowledgements}

We are grateful to Jacobeth Maloka and the staff of the Johannesburg Zoo for technical assistance, María Díez León for much help with references, Lis Jones for her proofreading the manuscript, and two anonymous referees for their helpful comments on an earlier draft of the paper. 
Funding was provided by the National Research Foundation (grant number: 2069110), the University of the Witwatersrand (Anderson Capelli Fund), and the Johannesburg Zoo.

\section{References}

Bremner-Harrison, S., Prodohl, P.A., Elwood, R.W., 2004. Behavioural trait assessment as a release criterion: boldness predicts early death in a reintroduction programme of captive-bred swift fox (Vulpes velox). Anim. Conserv. 7, 313-320.

Broom, D., Johnson, K., 1993. Stress and Animal Welfare. Chapman and Hall, London.

Callard, M.D., Bursten, S.N., Price, E.O., 2000. Repetitive backflipping behaviour in captive roof rats (Rattus rattus) and the effect of cage enrichment. Anim. Welf. 9, 139-152.

Cooper, J., Odberg, F., Nicol, C.J., 1996. Limitations on the effectiveness of environmental improvement in reducing stereotypic behaviour in bank voles (Clethrionomys glareolus). Appl. Anim. Behav. Sci. 48, 237-248.

Garner, J., Mason, G., 2002. Evidence for a relationship between cage stereotypies and behavioural disinhibition in laboratory rodents. Behav. Brain Res. 136, 83-92.

Gosling, S.D., 2001. From mice to men. What can we learn about personality from animal research? Psychol. Bull. 127, 45-86.

Jeppesen, L.L., Heller, K.E., Bildsøe, M., 2004. Stereotypies in female farm mink (Mustela vison) may be genetically transmitted and associated with higher fertility due to the effects on body weight. Appl. Anim. Behav. Sci. 86, 137-143.

Jones, M., Mason, G., Pillay, N., 2009. Towards understanding the typical low levels of stereotypic behaviour in captive animals caught from the wild. In: Proceedings of the 31st International Ethology Conference, Rennes, France.

Jones, M., van Lierop, M., Pillay, N., 2006. From housemouse to pentmouse: fitness consequences of stereotypy in the African Striped Mouse. In: Proceedings of the ASAB Winter Meeting, London, December 2006.

Jones, M., van Lierop, M., Pillay, N., 2008. All a mother's fault? Transmission of stereotypy in striped mice Rhabdomys. Appl. Anim. Behav. Sci. $115,82-89$.

Jule, K.R., Leaver, L.A., Lea, S.E.G., 2008. The effects of captive experience on reintroduction survival in carnivores: a review and analysis. Biol. Conserv. 141, 355-363.

Kiley, M., 1977. Stereotypies and their causation. Appl. Anim. Ethol. 3, 290-291.

Kleiman, D.G., 1996. Reintroduction programmes. In: Kleiman, D.G., Allen, M.E., Thompson, K.V., Lumpkin, S. (Eds.), Wild Mammals in Captivity: Principles and Techniques. The University of Chicago Press, Chicago and London, pp. 297-305.

Lewis, M.H., Presti, M.F., Lewis, J.B., Turner, C.A., 2006. The neurobiology of stereotypy I: environmental complexity. In: Mason, G., Rushen, J. (Eds.), Stereotypic Animal Behaviour: Fundamentals and Applications to Welfare. second ed. CAB International, Oxford, pp. 190-226.

Lynch, M., Walsh, B., 1998. Genetics and Analysis of Quantitative Traits. Sinauer Associates, Sunderland.

Marliave, J.B., Gergits, W.F., Aota, S., 1993. F 10 Pandalid shrimp: sex determination; DNA and dopamine as indicators of domestication; and outcrossing for wild pigment pattern. Zoo Biol. 12, 435-451.

Mason, G., 1991. Stereotypies: a critical review. Anim. Behav. 41, 10151037.

Mason, G., 2006a. Stereotypic behaviour in captive animals: fundamentals and implications for welfare and beyond. In: Mason, G., Rushen, J. (Eds.), Stereotypic Animal Behaviour: Fundamentals and Applications to Welfare. second ed. CAB International, Oxford, pp. 325-356.

Mason, G., 2006b. Are wild-born animals protected from stereotypy when placed in captivity? In: Mason, G., Rushen, J. (Eds.), Stereotypic Animal Behaviour: Fundamentals and Applications to Welfare. second ed. CAB International, Oxford, p. 196.

Mason, G., Clubb, R., Latham, N., Vickery, S., 2007. Why and how should we use environmental enrichment to tackle stereotypic behaviour? Appl. Anim. Behav. Sci. 102, 163-188.

Mason, G.J., Latham, N., 2004. Can't stop, won't stop: is stereotypy a reliable animal welfare indicator? Anim. Welf. 13, S57-S69.

Mason, G.J., Leipoldt, A., de Jonge, G., 1995. Why do female mink with high stereotypy levels have slow-growing offspring? In: Proceedings of the 29th International Congress of the ISAE, UFAW, UK, pp. 133-134.

McDougall, P.T., Réale, D., Sol, D., Reader, S.M., 2006. Wildlife conservation and animal temperament: causes and consequences of evolutionary change for captive, reintroduced, and wild populations. Anim. Conserv. 9, 39-48.

McPhee, M.E., 2003. Generations in captivity increases behavioural variance: considerations for captive breeding and reintroduction programs. Biol. Conserv. 11, 71-77.

Nel, K.N., 2003. The effects of dietary protein on the reproduction and behavioural characteristics of the striped mouse, Rhabdomys pumilio. MSc Thesis, University of the Witwatersrand.

Novak, M.A., Meyer, J.S., Lutz, C., Tiefenbacher, S., 2006. Social deprivation and social separation: developmental insights from primatology. In: Mason, G., Rushen, J. (Eds.), Stereotypic Animal Behaviour: Fundamentals and Applications to Welfare. second ed. CAB International, Oxford, pp. 153-189.

Ödberg, F., 1986. The jumping stereotypy in the bank vole (Clethrionomys glareolus). Biol. Behav. 11, 130-143.

Ödberg, F.O., 1987. The influence of cage size and environmental enrichment on the development of stereotypies in bank voles (Clethrionomys glareolus). Behav. Proc. 14, 155-173.

Perrin, M.R., 1980. The breeding strategies of two coexisting rodents, Rhabdomys pumilio (Sparrman, 1784) and Otomys irroratus (Brants, 1827): with a brief review of some pertinent life history ideas. Acta Oecol. 1, 383-410.

Pillay, N., 2000. Female mate preference and reproductive isolation in populations of the striped mouse Rhabdomys pumilio. Behaviour 137, 1431-1441.

Priestnall, R., 1972. Effects of litter size on the behaviour of lactating female mice (Mus musculus). Anim. Behav. 20, 386-394.

Schoenecker, B., Heller, K.E., 2000. Indication of a genetic basis of stereotypies in laboratory-bred bank voles (Clethrionomys glareolus). Appl. Anim. Behav. Sci. 68, 339-347.

Schønecker, B., 2009. Increased survival and reproductive success associated with stereotypical behaviours in laboratory-bred bank voles (Clethrionomys glareolus). Appl. Anim. Behav. Sci. 121, 55-62.

Schradin, C., Pillay, N., 2004. The striped mouse (Rhabdomys pumilio) from the Succulent karoo, South Africa: a territorial group-living solitary forager with communal breeding and helpers at the nest. J. Comp. Psychol. 118, 37-47.

Schwaibold, U., Pillay, N., 2001. Stereotypic behaviour is genetically transmitted in the African striped mouse Rhabdomys pumilio. Appl. Anim. Behav. Sci. 74, 273-280.

Seo, S., Kosaka, K., Sakamoto, N., Tokumoto, K., 1998. Tongue-playing and heart rate in calves. Appl. Anim. Behav. Sci. 58, 179-182.

Skinner, J.D., Chimimba, C.T., 2005. The Mammals of the Southern African Subregion, third ed. Cambridge University Press, Cape Town.

Smith, L.B., 1984. Electric field therapy for equine stereotypic behaviour. Anim. Behav. 45, 613-615.

Snyder, N.F.R., Derrickson, S.R., Beissinger, S.B., Wiley, J.W., Smith, T.B., Toone, W.D., Miller, B., 1996. Limitations of captive breeding in endangered species recovery. Conserv. Biol. 10, 338-348.

Sørensen, G., Randrup, A., 1986. Possible protective value of severe psychopathology against lethal effects of an unfavourable milieu. Stress Med. 2, 103-105.

StatSoft, Inc., 2006. STATISTICA (Data Analysis Software System), Version 7.1. , www.statsoft.com.

Svendsen, B., Hansen, J., Malmkvist, S., Palme, R., Jeppesen, L., 2007. Selection against stereotypic behaviour may have contradictory consequences for the welfare of farm mink (Mustela vison). Appl. Anim. Behav. Sci. 107, 110-119.

Swaisgood, R.R., 2007. Current status and future directions of applied behavioural research for animal welfare and conservation. Appl. Anim. Behav. Sci. 102, 139-162.

Swaisgood, R.R., Shepherdson, D.J., 2005. Scientific approaches to enrichment and stereotypies in zoo animals; what's been done and where should we go next? Zoo Biol. 24, 499-518.

Swaisgood, R.R., Shepherdson, D.J., 2006. Environmental enrichment for mitigating stereotypies in zoo animals. In: Mason, G., Rushen, J. (Eds.), Stereotypic Animal Behaviour: Fundamentals and Applications to Welfare. second ed. CAB International, Oxford, pp. 256285.

Vickery, S., Mason, G., 2004. Stereotypic behaviour in Asiatic Black and Malayan Sun bears. Zoo Biol. 23, 409-430.

Vickery, S.S., Mason, G.J., 2003. Behavioural persistence in captive bears: implications for reintroduction. Ursus 14, 35-43.

Wingfield, J.C., Sapolsky, R.M., 2003. Reproduction and resistance to stress: when and how. J. Neuroendocrinol. 15, 711-724.

Würbel, H., Garner, J., 2007. Refinement of Rodent Research Through Environmental Enrichment and Systematic Randomization. National Centre for the Replacement, Refinement and Reduction of Animals in Research available at www.nc3rs.org.uk.

Zar, J.H., 1996. Biostatistical Analysis, third ed. Prentice Hall, London. 